\title{
Measurement of Peak Expiratory Flow Rate (PEFR) to Predict Prevalence of Abdominal Muscle Weakness in Multipara Women-A Cross-Sectional Study
}

Sarawgi A*, Diwate A and Ahya $\mathbf{N}$

Department of Cardiovascular and Respiratory Sciences, Dr. Vithalroa Vikhe Patil College of Physiotherapy, Maharashtra University of Health Sciences, Nashik, India

\begin{abstract}
Due to multiparity, woman face abdominal weakness due to consecutive increase of size of uterus and hormonal changes and this can be measured using peak expiratory flow rate (PEFR). That force of expiration is less in multipara women than uniparous or nulliparous women since abdominal muscle are responsible for it. To evaluate the presence of abdominal muscle weakness in multipara woman by measuring peak expiratory flow rate. 100 participants were selected who were multipara women from 18-45 years of age and with postpartum period of at least one year women who were known case of hernia, stress incontinence, musculoskeletal disorder of spine, respiratory disorder or facial palsy. Material-Airflow $®$ Peak flow meter, Peak flow meter measurement and Manual Muscle testing of abdominal muscle were done and then the results were co related. By the acquired statistics it was concluded that there is no co-relation between the measurement of PEFR and prediction of abdominal weakness in multipara women. In future PEFR can be used as a test to detect abdominal weakness and further preventive measures can be taken.
\end{abstract}

Keywords: Manual Muscle testing; Peak expiratory flow rate (PEFR); Multiparity; Abdominal weakness; Peak flow meter

\section{Introduction}

Multipara means those who had delivered once or more after the age of viability. It includes primi-para (unipara-para 1) multipara (para 2,3,4) and grand multipara (para more than 4) [1]. During pregnancy, hormonal changes caused by relaxin, progesterone and estrogen combined with uterine growth may cause stretching of the abdominal muscles affecting mainly the rectus abdominis muscles. Also during pregnancy, it is common to have anterior pelvic tilt with or without lumbar hyperlordosis. These postural changes can affect the insertion angle of pelvic and abdominal muscles, influencing postural biomechanics. They can also generate a deficit in the support of the pelvic-abdominal organs. Furthermore, as the pregnancy progresses and the abdominal muscles stretch, there is a loss in the force vector of these muscles, and there may be a decrease in contraction strength. The occurrence of abdominal muscle weakness is more commonly seen in women who have multiple pregnancies, which may contribute to cumulative mechanical stress on the connective tissue of the abdominal wall causing repeated stretching of the muscle [2]. There is occurrence of diastasis recti abdominis (DRA) which is separation between the left and right side of the rectus abdominis muscle in pregnant women. While DRA was not detected in nulliparous group, it was present in $2 \%$ of primiparous and 59\% of multiparous patients [3].

The peak expiratory flow rate is a person's maximum speed of expiration, as measured with a peak flow meter, a small hand held device used to monitor a person's ability to breathe out air. It measures the airflow through the bronchi and thus the degree of obstruction in the airway. Peak expiratory flow rate represents a simple, non-invasive and cheap method of assessment of lung function [4]. Weakness of expiratory muscles is a common and prominent finding in multipara women [5]. Pregnancy is associated with profound respiratory changes, minute ventilation increase by almost $50 \%$, largely as a result of increased total volume [6]. Peak expiratory flow rate was found to be significantly lower among the pregnant females compared to the control $(\mathrm{p}<0.05)$. PEFR was also significantly decreased with increased gestational age $(\mathrm{p}=0.05, \mathrm{r}=0.78)$. This method helps to predict expiratory muscle weakness (Figure 1) [2].

Since due to multiparity, women face lot of complications due to weakness of abdominal muscles especially expiratory muscles like recti

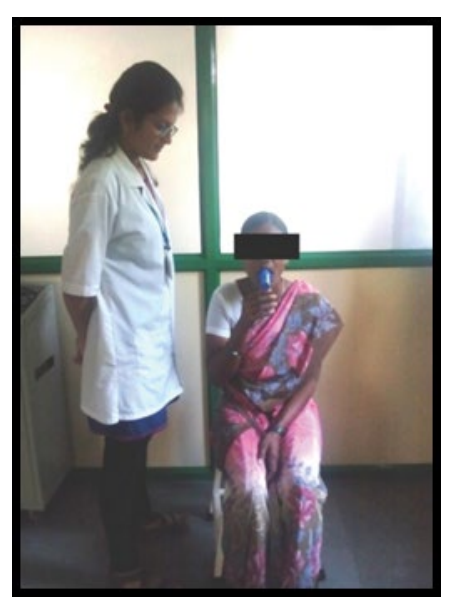

Figure 1: Measurement of PEFR.

*Corresponding author: Sarawgi A, Department of Cardiovascular and Respiratory Sciences, Dr. Vithalroa Vikhe Patil College of Physiotherapy, Maharashtra University of Health Sciences, Nashik, India, Tel: +9967054116; E-mail: meetaanchal14@gmail.com

Received: December 13, 2017; Accepted: January 25, 2018; Published: January 30, 2018

Citation: Sarawgi A, Diwate A, Ahya N (2018) Measurement of Peak Expiratory Flow Rate (PEFR) to Predict Prevalence of Abdominal Muscle Weakness in Multipara Women-A Cross-Sectional Study Physiother Rehabil 3: 153. doi: 10.4172/2573-0312.1000153

Copyright: (c) 2018 Sarawgi A, et al. This is an open-access article distributed under the terms of the Creative Commons Attribution License, which permits unrestricted use, distribution, and reproduction in any medium, provided the original author and source are credited. 
Citation: Sarawgi A, Diwate A, Ahya N (2018) Measurement of Peak Expiratory Flow Rate (PEFR) to Predict Prevalence of Abdominal Muscle Weakness in Multipara Women-A Cross-Sectional Study. Physiother Rehabil 3: 153. doi: 10.4172/2573-0312.1000153

Page 2 of 3

abdominis, it becomes important to evaluate the expiratory muscle force to predict the strength of the muscle using peak expiratory flow rate performed against an occluded airway after full expiration [2].

Due to multiparity, woman face abdominal weakness due to consecutive increase of size of uterus and hormonal changes and this can be measured using peak expiratory flow rate. That force of expiration is less in multipara women since abdominal muscle is responsible for it.

There have been very limited studies done on multiparity complications related to abdominal weakness and especially prediction of its severity using pulmonary expiratory flow rate. Since abdominal muscles are responsible for expiration especially recti abdominis. Pulmonary expiratory flow rate is very less comparative to normal woman and hence this is due to abdominal muscle weakness faced by the woman due to multiple pregnancy and regular increase in shape of the uterus. It even leads to rupture of uterus or hernia.

\section{Methodology}

In this cross sectional study, over a period of a year, 100 participants were selected according to convenient sampling, in Tandulvadi village of Vilad Ghat, who were multipara women from 18-45 years of age and with postpartum period of at least one year. Women who were known case of hernia, stress incontinence, musculoskeletal disorder of spine, respiratory disorder or facial palsy (Figures 2 and 3 ).

The study has been approved by Institutional Ethical Committee. Prospective subjects were explained about the proposed benefits, risks and procedures involved in the study, in a language best understood by them. Subject willing to participate in the study were screened for inclusive and exclusive criteria after receiving their informed consent. Subjects meeting the study criteria and willing to participate were included in the study. Peak flow meter measurements were taken

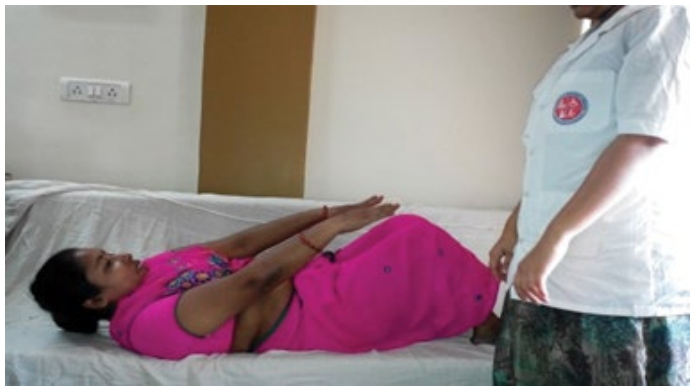

Figure 2: Checking upper abdominal MMT.

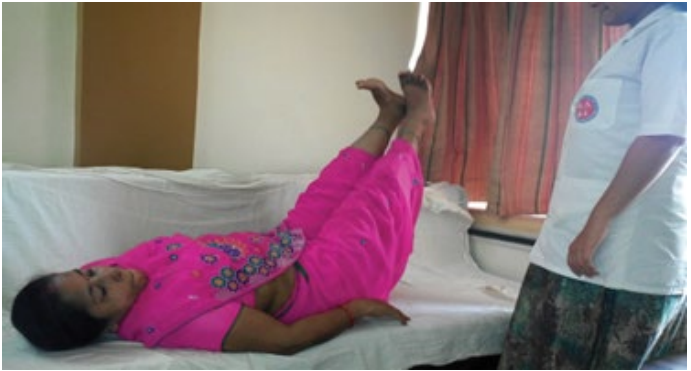

Figure 3: Checking lower abdominal MMT and Manual Muscle testing of abdominal muscle was done and then compared [7].

\section{Results}

According to Pearson Co-relation co-efficient graph from SPSS.16, it is noted that there is no co-relation between Manual Muscle testing of Upper Abdominal Muscle and Peak flow Meter Reading since " $r=1$ " (Tables 1 and 2) (Figure 4).

According to Pearson Co-relation co-efficient graph from SPSS.16, it is noted that there is no co-relation between Manual Muscle testing

\begin{tabular}{|c|c|c|}
\hline S.No. & Variables & Total Mean \\
\hline 1 & Age Of Participants & 39.69 \\
\hline 2 & No. Of Children & 2 \\
\hline
\end{tabular}

Table 1: Baseline about the participants included.

\begin{tabular}{|c|c|c|}
\hline Title & PFR & UMT \\
\hline \multirow{2}{*}{ PFR Pearson Co relation sig. (2 tailed)N } & 1 & 0.025 \\
\hline \multirow{2}{*}{ UMT Pearson Co relation sig. (2 tailed)N } & 100 & 0.803 \\
\hline & - & 100 \\
\hline & 0.025 & 1 \\
\hline & 0.803 & 100 \\
\hline
\end{tabular}

Table 2: Co-relation of peak flow meter and upper abdomen manual muscle testing

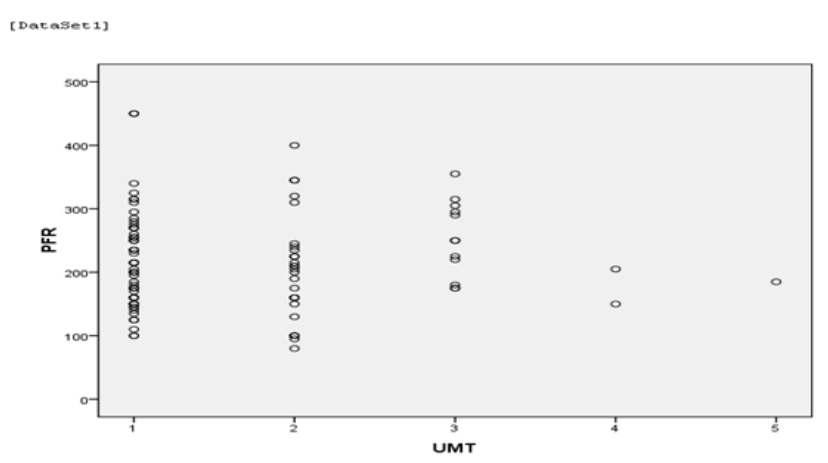

Figure 4: Co-relation between manual muscle testing of upper abdominal muscle and peak flow meter by using reading pearson co-relation co-efficient graph from SPSS.16.

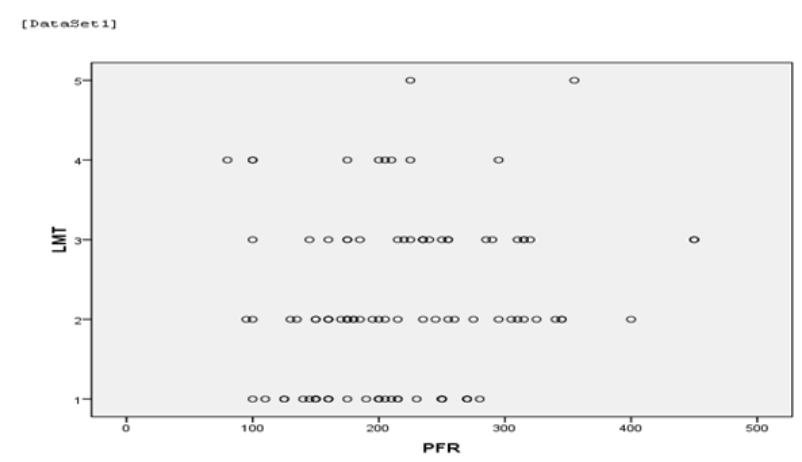

Figure 5: Co-relation between manual muscle testing of lower abdominal muscle and peak flow meter by using reading pearson co-relation co-efficient graph from SPSS.16. 
Citation: Sarawgi A, Diwate A, Ahya N (2018) Measurement of Peak Expiratory Flow Rate (PEFR) to Predict Prevalence of Abdominal Muscle Weakness in Multipara Women-A Cross-Sectional Study. Physiother Rehabil 3: 153. doi: 10.4172/2573-0312.1000153

Page 3 of 3

\begin{tabular}{|c|c|c|}
\hline Title & PFR & LMT \\
\hline \multirow{3}{*}{ PFR Pearson Co relation sig. (2 tailed)N } & 1 & 0.169 \\
\cline { 2 - 3 } & 100 & 0.093 \\
\cline { 2 - 3 } & - & 100 \\
\hline \multirow{2}{*}{ LMT Pearson Co relation sig. (2 tailed)N } & 0.169 & 1 \\
\cline { 2 - 3 } & 0.093 & 100 \\
\hline
\end{tabular}

Table 3: Co-relation of peak flow meter and lower abdomen manual muscle testing

of Lower Abdominal Muscle and Peak flow Meter Reading since " $r=1$ " (Figure 5).

By the acquired statistics it was concluded that there is no corelation between the measurement of PEFR and prediction of abdominal weakness in multipara women (Table 3).

\section{Discussion}

During pregnancy, hormonal changes caused by relaxin, progesterone and estrogen combined with uterine growth may cause stretching of the abdominal muscles affecting mainly the rectus abdominis muscles. Also during pregnancy, it is common to have anterior pelvic tilt with or without lumbar hyperlordosis. These postural changes can affect the insertion angle of pelvic and abdominal muscles, influencing postural biomechanics. They can also generate a deficit in the support of the pelvic-abdominal organs. Furthermore, as the pregnancy progresses and the abdominal muscles stretch, there is a loss in the force vector of these muscles, and there may be a decrease in contraction strength [2].

Peak expiratory flow rate (PEFR) is the simplest estimate for lung functions. It indicates the severity of airflow limitation. Peak expiratory flow rate is measured by peak expiratory flow meter (PEFM) which is a simple and relatively cheap device [8]. Expiration is a passive process but abdominal muscles are at play during forceful expiration, which is tested in Peak Expiratory Flow Rate.

Sanya Ao, Famuiyedi Ao conducted a study on Abdominal Muscle Strength and Some Respiratory Function Indices in subjects of varying parity status and concluded that while PEFR and abdominal muscle strength were significantly higher in the nulliparous group $(\mathrm{p}<0.05)$, vital capacity, a ventilatory parameter, was not significantly different in the two groups. The study concluded that the significantly lower abdominal muscle strength and PEFR in the post-parous subjects can be attributed to restrictive anatomical features of the rib cage.

But according to Pearson's co-relation co-efficient graph from SPSS.16, it is noted that there is no co-relation between Manual Muscle testing of upper abdominal muscle and Peak flow Meter reading since the " $r$ " value is 1 . It is believed that women with (Diastasis Recti Abdominis Muscle) DRAM have a greater number of pregnancies and deliveries; however the results of the present study showed that DRAM above the umbilicus has similar prevalence in primiparae and multiparae. This may be due to abdominal muscle weakness resulting from the last pregnancy in both groups.
Mean DRAM below the umbilicus was significantly higher among multiparae and had a weak correlation with DRAM above the umbilicus.

There was effect of posture. PEFR taken in upright position and MMT taken in supine position, that difference in activity were due to differences in the anatomy of the abdominal muscles and the influence of gravity.

\section{Conclusion}

There is no connection between PEFR and Abdominal Strength which indicates that even if there is abdominal weakness it does not necessarily results into low PEFR.

\section{Funding}

This study was funded by Maharashtra University of Health Sciences, Nashik through Short Term Research Grant.

\section{Acknowlegement}

I take this wonderful opportunity to thank all the "Hands" who have joined together to make this project successful. It is a proud privilege to express my overwhelming sense of gratitude to my esteemed, learned teacher Dr. S.D. Ganvir, Professor and Principal, DVVPF'S College of Physiotherapy, Ahmednagar, Dr. Abhijit Diwate Associate Professor, College of Physiotherapy, DVVPF'S, Ahmednagar, Dr. Nidhi Ahya, Assistant Professor, College of Physiotherapy DVVPF'S, Ahmednagar, Dr. Deepak Anap Associate Professor, College of Physiotherapy. DVVPF'S, Ahmednagar, who immensely helped and rendered their valuable advice, precious time, knowledge and relevant information regarding my study, and whose suggestions and guidance has enlightened me on this subject. would like to thank my study participants without whom this project could not have been possible. Last but not least I bow down to my Parents whose blessings, love, affection and encouragement has always been a catalyst in all walks of my life and without whose support, I would not have been where I am today.

\section{References}

1. Desai E, Leuva H, Leuva B, Kanani M (2013) A study of primary caesarean section in multipara. Int J Reprod Contracept Obstet Gynecol 2: 320-324.

2. Rett MT, Braga MD, Bernardes NO, Andrade SC (2009) Prevalence of diastasis of the rectus abdominis muscles immediately postpartum: Comparison between primiparae and multiparae. Rev Bras Fisioter 13: 275-280.

3. Volkan T, Cagdas C, Esengul T, Umit K (2011) Prevalence of diastasis recti abdominis in the population of young multiparous adults in Turkey. Ginekol Pol 82: 817-821.

4. Chinko BC, Green KI (2014) Peak expiratory flow rate of pregnant women in Port Harcourt. Int Res J Medical Sci 2: 1-5.

5. Sua'rez AA, Pessolano FA, Monteiro SG, Ferreyra G, Capria ME, et al. (2002) Peak flow and peak cough flow in the evaluation of expiratory muscle weakness and bulbar impairment in patients with neuro-muscular diseases. Am J Phys Med Rehabil 81: 506-511.

6. Artal R, O'Toole M (2003) Guidelines of the American college of obstetricians and gynecologists for exercise during pregnancy and the postpartum period. $\mathrm{Br}$ J Sports Med 37: 6-12.

7. Leiner GC, Abramowitz S, Small MJ, Stenby VB, Lewis WA (1963) Expiratory peak flow rate. Standard values for normal subjects. Use as a clinical test of ventilatory function. Am Rev Respir Dis 88: 644-651.

8. Al-Taweel AA, Kalantan KA, Ghani HA (1999) Peak expiratory flow rate in a sample of normal Saudi males at Riyadh, Saudi Arabia. J Family Community Med 6: 23-27. 